\title{
Interventional Stroke Care in the Era of COVID-19
}

\author{
Hisham Salahuddin ${ }^{1}$, Alicia C. Castonguay ${ }^{1}$, Syed F. Zaidi ${ }^{1,2}$, Richard Burgess ${ }^{1}$, \\ Ashutosh P. Jadhav ${ }^{3}$ and Mouhammad A. Jumaa ${ }^{1,2 *}$
}

${ }^{1}$ Department of Neurology, University of Toledo, Toledo, $\mathrm{OH}$, United States, ${ }^{2}$ Promedica Neurosciences Center, Toledo, $\mathrm{OH}$, United States, ${ }^{3}$ Department of Neurology, University of Pittsburgh Medical Center, Pittsburgh, PA, United States

OPEN ACCESS

Edited by:

Sunil Sheth,

University of Texas Health Science Center at Houston, United States

Reviewed by:

Sujan Teegala Reddy, University of Texas Health Science Center at Houston, United States Konark Malhotra Allegheny Health Network, United States

*Correspondence:

Mouhammad A. Jumaa mouhammad.jumaa@utoledo.edu

Specialty section:

This article was submitted to Endovascular and Interventional Neurology, a section of the journa Frontiers in Neurology

Received: 10 April 2020 Accepted: 29 April 2020

Published: 08 May 2020

Citation:

Salahuddin H, Castonguay AC, Zaidi SF, Burgess R, Jadhav AP and

Jumaa MA (2020) Interventional Stroke Care in the Era of COVID-19.

Front. Neurol. 11:468 doi: 10.3389/fneur.2020.00468
The current coronavirus disease (COVID-19) pandemic caused by severe acute respiratory syndrome coronavirus 2 has led to immense strain on healthcare systems and workers. Patients with severe symptoms of COVID-19 may also present with acute neurological emergencies such as ischemic stroke. Ischemic stroke in these patients may result from COVID-19 related complications or decompensation of previously asymptomatic cerebrovascular disorders, or concurrent ischemic stroke from common stroke risk factors in a patient with COVID-19. Acute ischemic stroke patients with large vessel occlusions require emergent triage, intensive care, and mechanical thrombectomy. Management of patients with large vessel occlusions (LVO) requires special considerations in the current pandemic. Physicians must now account for prognosis of severe COVID-19, resource utilization, and risk of infection to healthcare workers when determining eligibility for mechanical thrombectomy (MT). Here, we describe important prognostic factors including age, laboratory, and imaging findings to consider for MT selection and provide suggestions for taking care of patients with LVO and possible or confirmed COVID-19. It is recommended to perform MT in patients within the established guidelines, and consider a conservative approach in cases where there is clinical equipoise to minimize futile reperfusion. Lastly, we describe an illustrative case of a patient with ischemic stroke and COVID-19.

Keywords: CoVID-19, stroke, pandemic, thrombectomy, ischemic, coronavirus, cerebrovascular, neurointervention

\section{INTRODUCTION}

The novel severe acute respiratory syndrome coronavirus 2 (SARS-CoV-2), the causative agent of coronavirus disease 2019 (COVID-19), was first identified in Wuhan, China (1). High rates of transmissibility, primarily through airborne droplets and aerosols and international travel, have led to a worldwide pandemic. The United States (US) leads the world in the number of COVID19 cases, and there are growing concerns regarding the potential strain on its healthcare systems due to the intensive care needed for critically ill COVID-19 patients (2). Initial reports from other countries have already highlighted the stress of COVID-19 on their intensive care units (ICU) and resources (3). A recent case series of critically ill COVID-19 patients in Seattle, Washington reported a median ICU stay of 14 days and a median duration of mechanical ventilation of 10 days (4). With emergency departments and ICUs triaging and caring for increasing numbers of COVID19 patients, there is little doubt that the COVID-19 pandemic will have a tremendous impact on available resources for the triage and treatment of acute ischemic stroke (AIS). Here, we present an overview of COVID-19, recommendations for acute stroke care and treatment, and provide an illustrative case study of stroke in a COVID-19 positive patient. 


\section{COVID-19}

\section{Incidence and Mortality}

Overall mortality rates in COVID-19 are dependent on gender, age, and underlying co-morbidities (5). Males are more likely to have severe symptoms and have a higher rate of mortality than females $(6,7)$. In a study of 44,672 confirmed COVID19 patients in China, $80 \%$ of those who died were 65 years or older (8). Patients between 60 and 69, 70 and 79, and above 80 years of age have a mortality rate of $\sim 4,10$, and $21 \%$, respectively $(5,9)$. Patients with severe COVID-19 admitted to ICU have mortality rates of $\sim 26 \%$ (7). Furthermore, patients with co-morbidities are considered high-risk, specifically those with hypertension (10). Of 1,625 deaths in Italy, $25 \%$ of patients had one co-morbidity, $25 \%$ had two, almost half had three or more co-morbidities, and $<1 \%$ of patients did not have any co-morbidities (5). Shared risk factors for stroke and severe COVID-19 include diabetes mellitus, hypertension, coronary artery disease, and chronic kidney disease (11-13). In a Chinese study of 191 patients, hypertension (OR 3.05; 1.57-5.92), diabetes (OR $2.85 ; 1.35-6.05$ ), and coronary artery disease (OR 21.4; 4.698.7) were independently associated with death from COVID19 (10). Another study revealed that those with cardiovascular disease and an elevated troponin had a mortality rate of $69 \%$ (14).

Early studies of COVID-19 show that multiple factors contribute to high rates of mortality in selected populations. Patients from extended care facilities may have rates of mortality as high as $34 \%$ (15). In addition to considerations of age, comorbidities, lab, and imaging findings, the MuLBSTA scoring system for viral pneumonia has been shown to be an effective predictor of 90-day mortality. Presence of multilobe infiltrates, lymphopenia ( $\left.\leq 0.8 \times 10^{9} / \mathrm{L}\right)$, bacterial co-infection, smoking status, age, and hypertension are scored to give estimated mortality ranges from $2 \%$ to $>69 \%$ (16).

\section{Presentation \\ Symptoms}

Mean time from contact exposure to development of COVID19 symptoms is $\sim 5$ days, although a history of contact exposure or travel is not always present (17). The rate of asymptomatic carriers is currently unknown, but preliminary estimates range from 30 to $80 \%(18,19)$. Of those who develop clinical symptoms, $80 \%$ experience a mild clinical course (20). Presenting symptoms may include fever, cough, myalgia, and/or fatigue, and less commonly nausea or vomiting, sputum production, and diarrhea $(21,22)$. In one study, median time from onset of symptoms to hospitalization was 7 days, to development of dyspnea was 8 days, and to severe respiratory distress was 9 days (23). Patients with severe COVID-19 may develop severe respiratory distress, acute kidney injury, sepsis, secondary infection, coagulopathy, or acute cardiac injury at presentation or within a few days of admission (10). Patients who have longer times from symptom onset to hospitalization or present with respiratory distress are at higher risk of developing severe COVID-19 (24).

The WHO defines mild COVID-19 as patients with uncomplicated upper respiratory tract infections often with non-specific symptoms such as fever, cough, dyspnea, diarrhea, nausea, or vomiting. Severe COVID-19 is usually characterized by severe pneumonia (respiratory rate $>30 / \mathrm{min}$, severe respiratory distress, or oxygen saturation $\leq 93 \%$ ), acute respiratory distress syndrome, sepsis, or septic shock (25).

\section{Laboratory and Imaging Findings}

Although rapid bedside testing for COVID-19 is now available, multiple laboratory and imaging markers can help determine severe cases of COVID-19. Low white blood counts (WBC), low lymphocyte-to-WBC ratio, elevated bilirubin, C-Reactive Protein (CRP), D-dimer, and lactate dehydrogenase (LDH) may be markers in patients who develop severe disease $(21,22,24$, 26). Computed tomography (CT) chest imaging often reveals characteristic findings such as ground-glass opacities distributed in the lung periphery and patchy shadowing bilaterally, which can aid in determining the extent and severity of disease (27).

\section{Neurological Findings}

Initial reports from Wuhan, China revealed that $\sim 36.4 \%$ of severe COVID-19 patients develop neurological symptoms including impaired level of consciousness, headache, dizziness, seizures, dysgeusia, anosmia, dysphagia, and muscle pain $(28,29)$. Although patients with neurological symptoms are more likely to have severe COVID-19 disease, many present with neurological symptoms as the only presenting symptom of COVID-19. Anosmia is an early, common, specific, and often initial symptom of COVID-19, which may improve with resolution of illness (30). Anosmia and dysgeusia have been reported in over $85 \%$ of patients with infection (31). CNS involvement has been hypothesized to occur from hematogenous spread or direct involvement of the olfactory bulb and retrograde neuronal invasion $(32,33)$. Case reports of acute hemorrhagic necrotizing encephalopathy, meningoencephalitis, Miller Fisher syndrome, Guillain-Barre syndrome, and acute myelitis in COVID-19 patients have recently been described $(29,34-37)$. COVID-19 has also been detected in CSF and long term neurological sequelae of COVID-19 remain unknown (38).

\section{Stroke}

Ischemic stroke has been reported to occur in 5\% of COVID-19 patients admitted to hospital, which included patients with large vessel stenosis, small vessel disease, and cardioembolic strokes (39). Recent reports have emerged of patients younger than 50 years with LVO with minimal or no symptoms of COVID19 (40). However, most patients with stroke (ischemic stroke, cerebral venous thrombosis, and intracranial hemorrhage) are more likely to be older and present with severe COVID-19 symptoms (39). Mortality rates of patients with severe COVID19 and a history of cerebrovascular disease range from $20 \%$ (6 of 30$)$ to $100 \%$ (7 of 7$)(6,12)$. Multiple risk factors for severe COVID-19 have been identified, but cerebrovascular disease has been shown to be a negative prognostic factor in those with COVID-19 (39).

Numerous theories have emerged regarding the pathogenesis of severe disease in patients with COVID-19. For patients with stroke, a proinflammatory state triggered by cytokines may contribute to vascular endothelial injury or a hypercoagulable 
state which may result in extensive thrombosis and microvascular dysfunction (41-43). These hypotheses are supported by elevated D-dimers in patients with severe COVID-19, anecdotal reports of patients with ST-elevation myocardial infarction (STEMI) and normal coronary arteries (44), and reports of limb ischemia $(43,45)$. Furthermore, use of heparin has been shown to reduce mortality in patients with severe COVID-19 (46). Lung biopsy of a patient with COVID-19 has shown small vessel hyperplasia, vessel wall thickening, luminal stenosis, occlusion, and microthrombosis (47).

Ischemic stroke and COVID-19 may occur concurrently either from common stroke pathologies such as atrial fibrillation in patients with mild or asymptomatic COVID19, as a complication of severe COVID-19 pathology such as hypercoagulability or a proinflammatory state, or due to worsening hypoxia and decompensation in patients with previously asymptomatic cerebrovascular disorders such as carotid occlusion or moyamoya disease/syndrome.

\section{Acute Stroke Care Considerations}

Acute stroke care continues to be a vital part of emergency care, even amid a pandemic or crisis. The American Heart Association/American Stroke Association (AHA/ASA) has provided temporary emergency guidance for stroke centers during the current crisis which includes admission of stable stroke patients directly to step down units instead of the ICU and encourages the use of telemedicine for acute stroke patients (48). Acute ischemic stroke (AIS) patients with large vessel occlusions (LVO) benefit from mechanical thrombectomy (MT) within $24 \mathrm{~h}$ from "last seen normal" time (49-55). Although the use of intravenous tPA for AIS has not been studied in patients with COVID-19, its use is imperative for eligible patients with AIS. Given the current crisis, selection of patients for MT poses new challenges and requires refinement of established protocols. Recently published recommendations from the Society of NeuroInterventional Surgery (SNIS) recommend that MT should be performed in patients in which there is high-quality data to support benefit (56). The decision to perform MT in patients outside established guidelines should be pursued in the context of resource availability and balanced against the risks and benefits to the patient as well as the treating health-care providers.

Drastic changes have occurred during the current COVID19 crisis. Treatment goals have evolved from providing the best clinical care for patients to providing the best clinical care for patients without overutilization of resources or compromising healthcare worker safety. Treatment of life-threatening, time urgent conditions such as AIS and STEMI have always focused on providing the correct treatment for those who may benefit as early as possible. The concern of contact with possible COVID-19 positive patients may result in delayed treatment and triage, which has already been reported in China as doorto-device times for STEMI have increased by $25 \mathrm{~min}$ (57). Treatment of LVO will likely see similar increases in times as regional, hospital bypass, and mobile stroke unit protocols change, and healthcare workers don and doff personal protective equipment (PPE).
MT in patients older than 80 years of age has not been extensively evaluated in randomized clinical studies. In the HERMES meta-analysis, patients over 80 years had a mortality rate of $15.3 \%$ and a good clinical outcome in $29.8 \%$ (58). Realworld experience of patients undergoing MT over 80 years of age revealed a good functional outcome in $21 \%$ and a higher rate of intracranial hemorrhage than younger patients (59). Mortality in patients over 80 is significantly higher than younger patients (33 vs. 14\%) (60). Patients over 80 years of age also have high rates of futile reperfusion (50\%) (61). Although rates of mortality are higher in older patients, there remains a benefit in terms of functional clinical outcome in patients without COVID-19. The high rate of mortality of COVID-19 in this age group warrants careful evaluation of risks and benefits when mechanical thrombectomy is considered.

\section{Screening and Pre-hospital Care}

Early suspicion of COVID-19 in patients is vital for stroke team preparation. Screening for fever, contact with COVID + patients, and recent cough should ideally be performed by 911 dispatchers and EMT should be informed prior to on-scene arrival. For inpatient stroke codes, clinical information can be obtained from the patient's chart and nursing staff prior to inperson assessment. Telemedicine can be utilized both in the emergency department as well as for inpatient stroke codes to minimize provider contact with potential COVID-19 patients. Details of providing hyperacute stroke code care have been recently published (62). Urgent lab draws and rapid bedside testing for COVID-19 should be performed on arrival or during an inpatient code stroke, and if COVID-19 is suspected or clinical history cannot be obtained accurately, a CT chest may be performed prior to transport to the neuroangiography suite (NAS) (63).

\section{Patient Selection}

Prior to selecting patients for MT, risk factors for severe disease and mortality from COVID-19 and potential risks to healthcare workers need to be thoroughly evaluated. Patients for whom there is clinical equipoise, such as those with anterior or posterior circulation LVO and low NIHSS (National Institute of Health Stroke Scale), distal occlusions, low ASPECTS (Alberta Stroke Program Early CT Score), or minimal to moderate penumbral tissue, should be managed conservatively. Patients with an ASPECTS score of 5 or less have poor functional outcomes, high rates of futile reperfusion, and should be managed conservatively in the current climate $(64,65)$. Patients with low NIHSS and LVO, should be monitored closely, given possible subsequent clinical deterioration from COVID-19 related hypoxia or altered hemodynamics. In cases of subsequent clinical deterioration, MT should be performed if they meet established LVO guidelines. Institutions enrolling patients with clinical equipoise for MT in randomized clinical trials should halt enrollment and provide medical management in these patients for now.

Although LVO patients with clinical equipoise may be managed conservatively, denial of MT for patients within the established guidelines may lead to poorer clinical outcomes, 


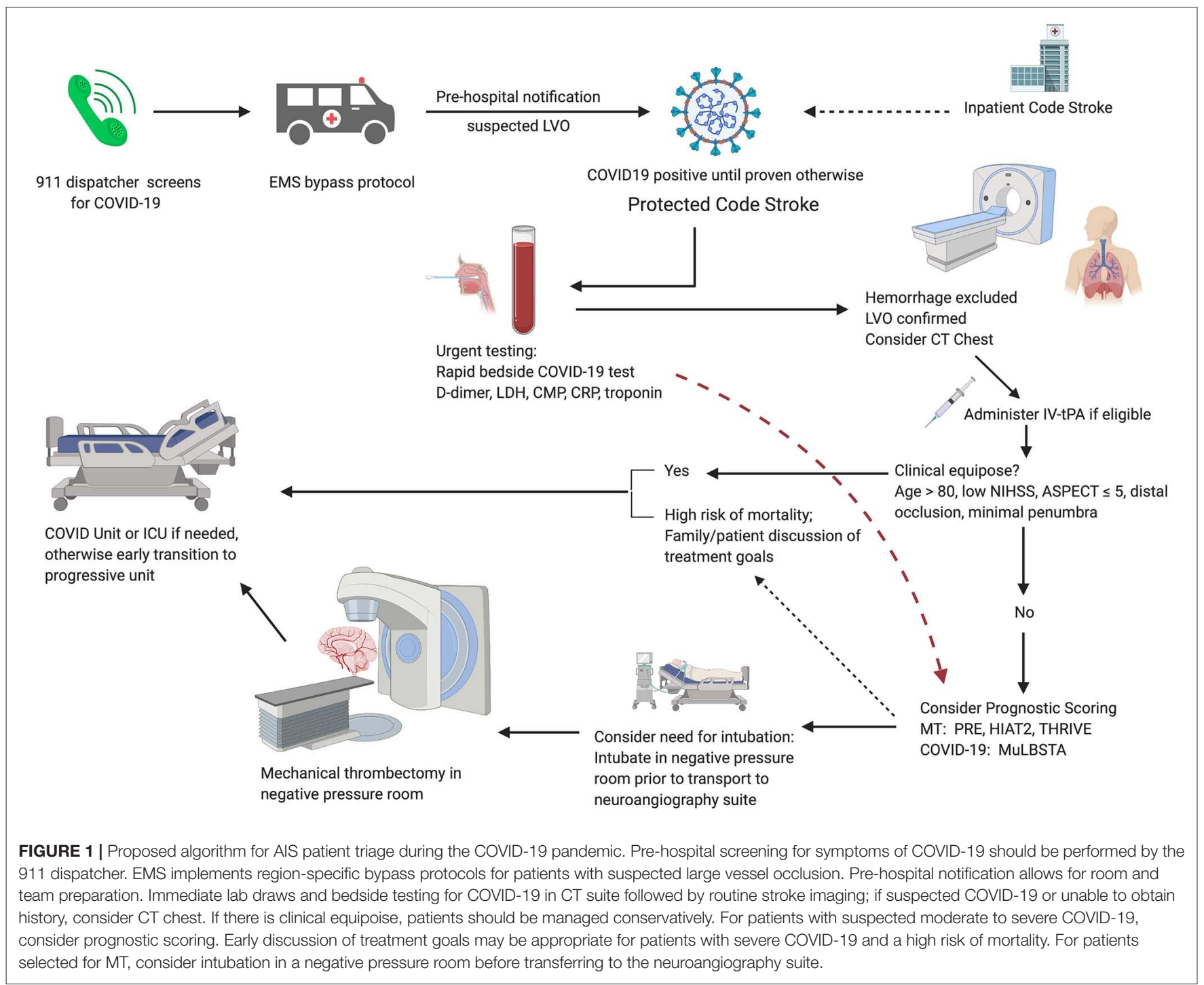

longer hospital stays, increased need for post-acute care and longterm skilled facility beds, and increased long-term cost of care and resource utilization $(56,66)$. With appropriate precautions, MT for patients younger than 80 years with LVO and suspected COVID-19 who may potentially benefit is a reasonable approach. In patients younger than 80 years with suspected moderate to severe COVID-19, use of pre-treatment thrombectomy scores such as HIAT2 (67), THRIVE (68), and PRE (69) in conjunction with COVID-19 predictors may provide important insight to guide discussions of treatment goals and expectations of longterm clinical outcome (See Figure 1 for proposed algorithm for patients with suspected LVO).

\section{Anesthesia and Sedation}

Conscious sedation can be performed in patients in whom there is a low risk of intra-procedural conversion to general anesthesia and can maintain sufficient oxygenation without the use of supplemental oxygen. Randomized clinical trials have shown that general anesthesia is safe for patients undergoing MT and should be considered for all MT patients during the COVID-19 pandemic $(70,71)$. Patients with respiratory failure, need for oxygen supplementation to maintain $\mathrm{SpO}_{2} \geq 92 \%$ and $\mathrm{PaO}_{2}>60 \mathrm{mmHg}$, or active cough should be intubated in a negative pressure room before transport to the NAS $(72,73)$. Extension tubing should be set up to avoid circuit disconnections or ventilator transfers once in the NAS. Providers should aim to avoid suctioning during the procedure and nonintubated patients should be provided masks to wear during the procedure.

\section{Neuroangiography Suite}

Negative pressure rooms should ideally have self-closing doors with a negative pressure anteroom to allow for patient transport and an area for donning and doffing. Negative pressure rooms provide a pressure differential between the room and surrounding environment and ensure that the 


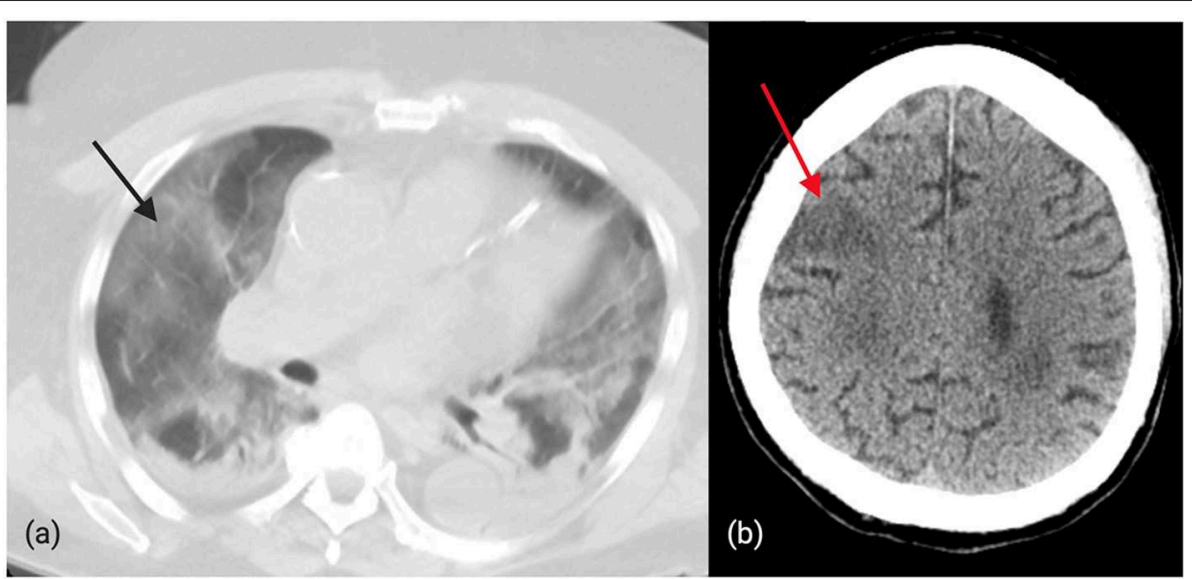

FIGURE 2 | (a): Diffuse, bilateral ground-glass opacities in a patient with confirmed COVID-19 and distal MCA occlusion. (b): CT brain revealing ischemic changes in the right cortical MCA territory in a patient with COVID-19.

total mechanically supplied air is less than that of the total mechanically exhausted air. This can be achieved by placing a high-efficiency particulate air (HEPA) filter exhausting clean air back to the air system or through a window to the atmosphere and sealing any other exhaust/return air ducts. A pressure monitor should be visible in the room to ensure a pressure differential of $-2.5 \mathrm{~Pa}$ has been reached. This can be achieved by increasing the flow on the HEPA machine and should provide at least 12 air changes per hour (74). Due to time constraints and architectural challenges in most NAS, it may be reasonable to perform MT in a designated negative pressure COVID swing single plane suite that can be shared with interventional cardiology and/or interventional radiology.

\section{Mechanical Thrombectomy Procedure and Room Set-Up}

Providers should perform all MT with the presumption that patients are COVID-19 positive and wear standard PPE (surgical cap, eye protection, full gown, gloves, shoe covers) and an N95 mask. Prior to MT, all unnecessary equipment should be removed from the NAS and all remaining equipment such as anesthesia machines and other surfaces should be covered with a protective covering. Only equipment and staff necessary for the procedure should be in the room at the onset of the procedure. Supporting staff should be identified as "hot" (exposed to patient) or "cold" (not exposed to patient) prior to the procedure. A "cold" nurse or technician should be available in full PPE in the control room in case additional supplies are needed or if the "hot" technician becomes contaminated. Simulation training with the entire team should be performed to help identify early issues and improve team preparation. If emergent intubation is required during the procedure, all personal should leave the room except those essential for immediate patient care. Signs should be placed on the NAS indicating an ongoing procedure on COVID-19 positive or suspected patient. Current SNIS recommendations include early transition of stroke patients to the step-down unit to minimize the use of ICU beds (56).

When negative pressure rooms are not available, the use of an anteroom is more important, and "foot traffic" near the neuroangiography suite should be minimized. In positive pressure neuroangiography suites, environmental services should wait $207 \mathrm{~min}$ or run a HEPA filter in the room for about $20 \mathrm{~min}$ before entering the room (75). Terminal cleaning with an EPA registered, hospital-grade disinfectant must be performed between patients. This includes, but is not limited, to disinfecting the floor and walls, all surfaces, especially high touch areas, cables, anesthesia machines, and trash receptacles. The thorough cleaning of the neuroangiography suite often takes about an hour before the room can be turned around.

\section{CASE STUDY}

Recently, a 75-year-old man with right gaze deviation and left arm drift (initial NIHSS 12) presented to our hospital. The patient was identified by bypass protocols to have a suspected LVO based on the Rapid Arterial oCclusion Evaluation (RACE) score and was brought directly to our comprehensive stroke center. Initial pre-hospital page from emergency medical services (EMS) identified the patient as suspected COVID-19 positive with recent respiratory symptoms as well as "RACE positive." On arrival, the patient was met by one nurse, CT technician, and physician in PPE. In addition to neuroimaging, a CT chest (Figure 2) was performed which revealed diffuse ground-glass opacities consistent with COVID-19. Vascular imaging revealed a distal right MCA M3 branch occlusion with matching infarct, and labs revealed an elevated troponin (0.26), elevated AST (50), bilirubin (1.3), LDH (523), CRP (27), ferritin (393), and procalcitonin (2.2). Given the lack of clinical-core mismatch, reperfusion therapy was not offered. The patient required intubation and within 2 days, the patient passed away from respiratory failure and shock. 


\section{CONCLUSION}

COVID-19 has placed an unprecedented strain on healthcare systems and resources. Our review summarizes the clinical presentation of COVID-19 and provides prognostic features of severe COVID-19 infection to help determine the risks and benefits of performing MT. While the provided algorithm accounts for many considerations for MT in the current climate, the decision to perform MT is complex and should be individualized. Furthermore, there is a lack of literature on outcomes of MT in LVO patients with COVID-19 and these opinions are based on expert views and anecdotal reports.

Although stroke physicians and neurointerventionalists may not be at the forefront of the COVID-19 battle, we must work to support and protect all other healthcare workers and their families, minimize futile reperfusion, reduce neuroangiography suite turnover, limit PPE use, and ensure that all ventilators and other resources are used for patients who would most likely benefit. In a time when most systems are overwhelmed, canceling elective procedures and minimizing non-urgent diagnostic

\section{REFERENCES}

1. WHO. Novel Coronavirus - China. (2020). Available online at: http://www. who.int/csr/don/12-january-2020-novel-coronavirus-china/en/ (accessed April 4, 2020).

2. Adalja AA, Toner E, Inglesby TV. Priorities for the US health community responding to COVID-19. JAMA. (2020). doi: 10.1001/jama.2020.3413. [Epub ahead of print].

3. Remuzzi A, Remuzzi G. COVID-19 and Italy: what next? Lancet. (2020) 395:1225-8. doi: 10.1016/S0140-6736(20)30627-9

4. Bhatraju PK, Ghassemieh BJ, Nichols M, Kim R, Jerome KR, Nalla AK, et al. Covid-19 in critically Ill Patients in the seattle region - case series. $N$ Engl J Med. (2020). doi: 10.1056/NEJMoa2004500. [Epub ahead of print].

5. Onder G, Rezza G, Brusaferro S. Case-fatality rate and characteristics of patients dying in relation to COVID-19 in Italy. JAMA. (2020) doi: 10.1001/jama.2020.4683. [Epub ahead of print].

6. Yang X, Yu Y, Xu J, Shu H, Xia Ja, Liu H, et al. Clinical course and outcomes of critically ill patients with SARS-CoV-2 pneumonia in Wuhan, China: a single-centered, retrospective, observational study. Lancet Respir Med. (2020). doi: 10.1016/S2213-2600(20)30079-5. [Epub ahead of print].

7. Grasselli G, Zangrillo A, Zanella A, Antonelli M, Cabrini L, Castelli A, et al. Baseline characteristics and outcomes of (1591). Patients infected with sars-CoV-2 admitted to ICUs of the Lombardy Region, Italy. JAMA. (2020) 323:1574-81. doi: 10.1001/jama.2020.5394

8. Novel Coronavirus Pneumonia Emergency Response Epidemiology T. The epidemiological characteristics of an outbreak of 2019 novel coronavirus diseases (COVID-19) in China. Zhonghua Liu Xing Bing Xue Za Zhi. (2020) 41:145-51. doi: 10.3760/cma.j.issn.0254-6450.2020.02.003

9. Report of the WHO-China Joint Mission on Coronavirus Disease 2019 (COVID-19) (2020). Available online at: https://www.who.int/docs/defaultsource/coronaviruse/who-china-joint-mission-on-covid-19-final-report.pdf

10. Zhou F, Yu T, Du R, Fan G, Liu Y, Liu Z, et al. Clinical course and risk factors for mortality of adult inpatients with COVID-19 in Wuhan, China: a retrospective cohort study. Lancet. (2020) 395:1054-62. doi: 10.1016/S0140-6736(20)30566-3

11. Henry BM, Lippi G. Chronic kidney disease is associated with severe coronavirus disease (2019). (COVID-19) infection. Int Urol Nephrol. (2020). doi: 10.1007/s11255-020-02451-9. [Epub ahead of print].

12. Guan WJ, Liang WH, Zhao Y, Liang HR, Chen ZS, Li YM, et al. Comorbidity and its impact on 1590 patients with Covid-19 in China: a nationwide analysis. Eur Respir J. (2020). doi: 10.1183/13993003.01227-2020 procedures will free up manpower to take care of COVID19 patients and reduce healthcare workers' burden. We must continue to advocate for our stroke patients and intervene on patients when we are confident that the risks taken, for the patient as well as the healthcare team are less than the benefits.

\section{ETHICS STATEMENT}

Written informed consent was not obtained from the individual(s) for the publication of any potentially identifiable images or data included in this article.

\section{AUTHOR CONTRIBUTIONS}

HS contributed substantially to the conception and design of the study, drafted and provided critical revision of the article. AC, SZ, $\mathrm{RB}$, and $\mathrm{AJ}$ contributed substantially to design of the study and critical revision of the article. MJ contributed substantially to the conception and design of the study, provided critical revision of the article, and provided final approval of the version to publish.

13. Wang D, Hu B, Hu C, Zhu F, Liu X, Zhang J, et al. Clinical characteristics of 138 hospitalized patients with (2019). Novel coronavirus-infected pneumonia in Wuhan, China. JAMA. (2020) 323:1061-9. doi: 10.1001/jama.2020.1585

14. Guo T, Fan Y, Chen M, Wu X, Zhang L, He T, et al. Cardiovascular implications of fatal outcomes of patients with coronavirus disease (2019). (COVID-19). JAMA Cardiol. (2020) 27:e201017. doi: 10.1001/jamacardio.2020.1017

15. McMichael TM, Currie DW, Clark S, Pogosjans S, Kay M, Schwartz NG, et al. Epidemiology of Covid-19 in a long-term care facility in king county, Washington. N Engl J Med. (2020). doi: 10.1056/NEJMoa2005412. [Epub ahead of print].

16. Chen N, Zhou M, Dong X, Qu J, Gong F, Han Y, et al. Epidemiological and clinical characteristics of 99 cases of 2019 novel coronavirus pneumonia in Wuhan, China: a descriptive study. Lancet. (2020) 395:507-13. doi: 10.1016/S0140-6736(20)30211-7

17. Li Q, Guan X, Wu P, Wang X, Zhou L, Tong Y, et al. Early transmission dynamics in Wuhan, China, of novel coronavirus-infected pneumonia. N Engl J Med. (2020) 382:1199-207. doi: 10.1056/NEJMoa20 01316

18. Day M. Covid-19: four fifths of cases are asymptomatic, China figures indicate. BMJ. (2020) 369:m1375. doi: 10.1136/bmj.m1375

19. Nishiura H, Kobayashi T, Suzuki A, Jung SM, Hayashi K, Kinoshita $\mathrm{R}$, et al. Estimation of the asymptomatic ratio of novel coronavirus infections (COVID-19). Int J Infect Dis. (2020) 94:154-155. doi: 10.1016/j.ijid.2020.03.020

20. Wu Z, McGoogan JM. Characteristics of and important lessons from the coronavirus disease (2019). (COVID-19) Outbreak in China: summary of a report of 72314 cases from the Chinese center for disease control and prevention. JAMA. (2020). doi: 10.1001/jama.2020.2648. [Epub ahead of print].

21. Guan WJ, Ni ZY, Hu Y, Liang WH, Ou CQ, He JX, et al. Clinical characteristics of coronavirus disease 2019 in China. N Engl J Med. (2020) 382:1708-20. doi: 10.1056/NEJMoa2002032

22. Liu W, Tao ZW, Lei W, Ming-Li Y, Kui L, Ling Z, et al. Analysis of factors associated with disease outcomes in hospitalized patients with 2019 novel coronavirus disease. Chin Med J. (2020) 133:1032-1038. doi: $10.1097 / C M 9.0000000000000775$

23. Huang C, Wang Y, Li X, Ren L, Zhao J, Hu Y, et al. Clinical features of patients infected with 2019 novel coronavirus in Wuhan, China. Lancet. (2020) 395:497-506. doi: 10.1016/S0140-6736(20) 30183-5 
24. Deng Y, Liu W, Liu K, Fang YY, Shang J, Zhou L, et al. Clinical characteristics of fatal and recovered cases of coronavirus disease (2019). (COVID-19) in Wuhan, China: a retrospective study. Chin Med J. (2020). doi: 10.1097/CM9.0000000000000824. [Epub ahead of print].

25. Clinical Management of Severe Acute Respiratory Infection (SARI) When COVID-19 Disease Is Suspected: Interim Guidance V 1.2. World Health Organization (2020). Available online at: https://www.who.int/publicationsdetail/clinical-management-of-severe-acute-respiratory-infection-whennovel-coronavirus-(ncov)-infection-is-suspected

26. Wu C, Chen X, Cai Y, Xia J, Zhou X, Xu S, et al. Risk factors associated with acute respiratory distress syndrome and death in patients with coronavirus disease 2019 pneumonia in Wuhan, China. JAMA Intern Med. (2020). doi: 10.1001/jamainternmed.2020.0994. [Epub ahead of print].

27. Zhou S, Wang Y, Zhu T, Xia L. CT features of coronavirus disease 2019 (COVID-19) pneumonia in 62 patients in Wuhan, China. AJR Am J Roentgenol. (2020) 1-8. doi: 10.2214/AJR.20.22975. [Epub ahead of print].

28. Mao L, Wang M, Chen S, He Q, Chang J, Hong C, et al. Neurological manifestations of hospitalized patients with COVID-19 in Wuhan, China: a retrospective case series study. JAMA Neurol. (2020). doi: 10.2139/ssrn.3544840. [Epub ahead of print].

29. Poyiadji N, Shahin G, Noujaim D, Stone M, Patel S, Griffith B. COVID-19associated acute hemorrhagic necrotizing encephalopathy: ct and mri features. Radiology. (2020). doi: 10.1148/radiol.2020201187

30. Rachel Kaye KK, Jean Brereton, James C. Denneny III. COVID-19 anosmia reporting tool: initial findings. Otolaryngol Head Neck Surg. (2020). doi: 10.1177/0194599820922992. [Epub ahead of print].

31. Lechien JR, Chiesa-Estomba CM, De Siati DR, Horoi M, Le Bon SD, Rodriguez A, et al. Olfactory and gustatory dysfunctions as a clinical presentation of mild-to-moderate forms of the coronavirus disease (COVID19): a multicenter European study. Eur Arch Otorhinolaryngol. (2020). doi: 10.1007/s00405-020-05965-1. [Epub ahead of print].

32. Mao L, Jin H, Wang M, Hu Y, Chen S, He Q, et al. Neurologic manifestations of hospitalized patients with coronavirus Disease 2019 in Wuhan, China. JAMA Neurol. (2020) e201127. doi: 10.1001/jamaneurol.2020.1127. [Epub ahead of print].

33. Baig AM, Khaleeq A, Ali U, Syeda H. Evidence of the COVID-19 virus targeting the CNS: tissue distribution, host-virus interaction, and proposed neurotropic mechanisms. ACS Chem Neurosci. (2020) 11:995-8. doi: 10.1021/acschemneuro.0c00122

34. Zhao K, Huang J, Dai D, Feng Y, Liu L, Nie S. Acute myelitis after SARS-CoV-2 infection: a case report. Available online at: https://www.medrxiv.org/content/ 10.1101/2020.03.16.20035105v1.full.pdf. (accessed April 08, 2020).

35. Zhao H, Shen D, Zhou H, Liu J, Chen S. Guillain-Barre syndrome associated with SARS-CoV-2 infection: causality or coincidence? Lancet Neurol. (2020) 19:383-4. doi: 10.1016/S1474-4422(20)30109-5

36. Moriguchi T, Harii N, Goto J, Harada D, Sugawara H, Takamino J, et al. A first case of meningitis/encephalitis associated with SARS-coronavirus-2. Int J Infect Dis. (2020) 94:55-8. doi: 10.1016/j.ijid.2020.03.062

37. Gutierrez-Ortiz C, Mendez A, Rodrigo-Rey S, San Pedro-Murillo E, Bermejo-Guerrero L, Gordo-Manas R, et al. Miller fisher syndrome and polyneuritis cranialis in COVID-19. Neurology. (2020). doi: 10.1212/WNL.0000000000009619. [Epub ahead of print].

38. Zhou L, Zhang M, Gao J, Wang J. Sars-Cov-2: Underestimated damage to nervous system. Travel Med Infect Dis. (2020) 101642. doi: 10.1016/j.tmaid.2020.101642. [Epub ahead of print].

39. Li Y, Wang M, Zhou Y, Chang J, Xian Y, Mao L, et al. Acute cerebrovascular disease following COVID-19: a single center, retrospective, observational study. SSRN Electronic J. (2020). doi: 10.2139/ssrn. 3550025

40. Oxley TJ, Mocco J, Majidi S, Kellner CP, Shoirah H, Paul Singh I, et al. LargeVessel Stroke as a Presenting Feature of Covid-19 in the Young. N Engl J Med. (2020). doi: 10.1056/NEJMc2009787

41. Mei Heng HY. Characteristics, causes, diagnosis and treatment of coagulation dysfunction in patients with COVID-19. Chin J Hematol. (2020) 41. doi: 10.3760/cma.j.issn.0253-2727.2020.0002

42. Thachil J. The versatile heparin in COVID-19. J Thromb Haemost. (2020) 18:1020-2. doi: 10.1111/jth.14821
43. Li $\mathrm{T}$, Lu $\mathrm{H}$, Zhang $\mathrm{W}$. Clinical observation and management of COVID-19 patients. Emerg Microbes Infect. (2020) 9:687-90. doi: 10.1080/22221751.2020.1741327

44. Wood S. COVID-19 and the heart: insights from the front lines. tctMD. (2020). Available online at: https://www.tctmd.com/news/covid-19and-heart-insights-front-lines

45. Zhang Y, Cao W, Xiao M, Li YJ, Yang Y, Zhao J, et al. [Clinical and coagulation characteristics of 7 patients with critical COVID-2019 pneumonia and acro-ischemia]. Zhonghua Xue Ye Xue Za Zhi. (2020) 41:E006. doi: 10.3760/cma.j.issn.0253-2727.2020.0006

46. Tang N, Bai H, Chen X, Gong J, Li, D Sun, Z. Anticoagulant treatment is associated with decreased mortality in severe coronavirus disease 2019 patients with coagulopathy. J Thromb Haemost. (2020) 18:1094-9. doi: $10.1111 /$ jth.14817

47. Luo W, Yu, H, Gou, J, Li X, Sun Y, Li J, et al. Clinical pathology of critical patient with novel coronavirus pneumonia (COVID-19). [Preprint]. (2020) 2020020407.

48. Temporary emergency guidance to US stroke centers during the COVID19 Pandemic. Stroke. (2020). doi: 10.1161/STROKEAHA.120.030023.[Epub ahead of print].

49. Berkhemer OA, Fransen PS, Beumer D, van den Berg LA, Lingsma HF, Yoo AJ, et al. A randomized trial of intraarterial treatment for acute ischemic stroke. N Engl J Med. (2015) 372:11-20. doi: 10.1056/NEJMoa1411587

50. Jovin TG, Chamorro A, Cobo E, de Miquel MA, Molina CA, Rovira A, et al. Thrombectomy within 8 hours after symptom onset in ischemic stroke. N Engl J Med. (2015) 372:2296-306. doi: 10.1056/NEJMoa1503780

51. Saver JL, Goyal M, Bonafe A, Diener HC, Levy EI, Pereira VM, et al. Stentretriever thrombectomy after intravenous t-PA vs. t-PA alone in stroke. N Engl J Med. (2015) 372:2285-95. doi: 10.1056/NEJMoa1415061

52. Goyal M, Demchuk AM, Menon BK, Eesa M, Rempel JL, Thornton J, et al. Randomized assessment of rapid endovascular treatment of ischemic stroke. N Engl J Med. (2015) 372:1019-30. doi: 10.1056/NEJMoa1414905

53. Campbell BC, Mitchell PJ, Kleinig TJ, Dewey HM, Churilov L, Yassi N, et al. Endovascular therapy for ischemic stroke with perfusion-imaging selection. $N$ Engl J Med. (2015) 372:1009-18. doi: 10.1056/NEJMoa1414792

54. Albers GW, Marks MP, Kemp S, Christensen S, Tsai JP, Ortega-Gutierrez S, et al. Thrombectomy for stroke at 6 to 16 hours with selection by perfusion imaging. N Engl J Med. (2018) 378:708-18. doi: 10.1056/NEJMoa1713973

55. Nogueira RG, Jadhav AP, Haussen DC, Bonafe A, Budzik RF, Bhuva P, et al. Thrombectomy 6 to 24 hours after stroke with a mismatch between deficit and infarct. N Engl J Med. (2018) 378:11-21. doi: 10.1056/NEJMoa1706442

56. Fraser JF, Arthur A, Chen M, Levitt M, Mocco J, Albuquerque F, et al. Society of neurointerventional surgery recommendations for the care of emergent neurointerventional patients in the setting of COVID-19. J Neurointerv Surg. (2020). doi: 10.1136/neurintsurg-2020-016098. [Epub ahead of print].

57. Tam CF, Cheung KS, Lam S, Wong A, Yung A, Sze M, et al. Impact of coronavirus disease 2019 (COVID-19) outbreak on ST-segment-elevation myocardial infarction care in Hong Kong, China. Circ Cardiovasc Qual Outcomes. (2020). 13:e006631. doi: 10.1161/CIRCOUTCOMES.120.006631

58. Goyal M, Menon BK, van Zwam WH, Dippel DW, Mitchell PJ, Demchuk AM, et al. Endovascular thrombectomy after large-vessel ischaemic stroke: a metaanalysis of individual patient data from five randomised trials. Lancet. (2016) 387:1723-31. doi: 10.1016/S0140-6736(16)00163-X

59. Alawieh A, Starke RM, Chatterjee AR, Turk A, De Leacy R, Rai AT, et al. Outcomes of endovascular thrombectomy in the elderly: a 'real-world' multicenter study. J Neurointerv Surg. (2019) 11:545-53. doi: 10.1136/neurintsurg-2018-014289

60. Rezai MK, Advani R, Dalen I, Fjetland L, Kurz KD, Kurz MW. Endovascular thrombectomy in the elderly: do radiological and clinical outcomes differ from those in younger patients? A prospective single-center experience. Cerebrovasc Dis. (2019) 47:65-71. doi: 10.1159/000497315

61. Slawski DE, Salahuddin H, Shawver J, Kenmuir CL, Tietjen GE, Korsnack A, et al. Mechanical thrombectomy in elderly stroke patients with mild-to-moderate baseline disability. Interv Neurol. (2018) 7:246-55. doi: 10.1159/000487333

62. Khosravani H, Rajendram P, Notario L, Chapman MG, Menon BK. Protected code stroke: hyperacute stroke management during the 
coronavirus disease 2019. (COVID-19) pandemic. Stroke. (2020). doi: 10.1161/STROKEAHA.120.029838. [Epub ahead of print].

63. FDA. Authorization for ID NOW COVID-19. (2020). Available online at: https://www.fda.gov/media/136525/download (accessed April 8, 2020).

64. Yoo AJ, Zaidat OO, Chaudhry ZA, Berkhemer OA, Gonzalez RG, Goyal M, et al. Impact of pretreatment noncontrast CT alberta stroke program early CT score on clinical outcome after intra-arterial stroke therapy. Stroke. (2014) 45:746-51. doi: 10.1161/STROKEAHA.113.004260

65. Sarraj A, Hassan AE, Savitz S, Sitton C, Grotta J, Chen P, et al. Outcomes of endovascular thrombectomy vs medical management alone in patients with large ischemic cores: a secondary analysis of the optimizing patient's selection for endovascular treatment in acute ischemic stroke (select) study. JAMA Neurol. (2019) 76:1147-56. doi: 10.1001/jamaneurol.2019.2109

66. Campbell BCV, Mitchell PJ, Churilov L, Keshtkaran M, Hong KS, Kleinig TJ, et al. Endovascular thrombectomy for ischemic stroke increases disability-free survival, quality of life, and life expectancy and reduces cost. Front Neurol. (2017) 8:657. doi: 10.3389/fneur.2017.00657

67. Sarraj A, Albright K, Barreto AD, Boehme AK, Sitton CW, Choi J, et al. Optimizing prediction scores for poor outcome after intra-arterial therapy in anterior circulation acute ischemic stroke. Stroke. (2013) 44:3324-30. doi: 10.1161/STROKEAHA.113.001050

68. Flint AC, Xiang B, Gupta R, Nogueira RG, Lutsep HL, Jovin TG, et al. THRIVE score predicts outcomes with a third-generation endovascular stroke treatment device in the TREVO-2 trial. Stroke. (2013). 44: 3370-5. doi: 10.1161/STROKEAHA.113.002796

69. Rangaraju S, Aghaebrahim A, Streib C, Sun CH, Ribo M, Muchada M, et al. Pittsburgh response to endovascular therapy (PRE) score: optimizing patient selection for endovascular therapy for large vessel occlusion strokes. $J$ Neurointerv Surg. (2015) 7:783-8. doi: 10.1136/neurintsurg-2014-011351

70. Schonenberger S, Uhlmann L, Hacke W, Schieber S, Mundiyanapurath S, Purrucker JC, et al. Effect of conscious sedation vs general anesthesia on early neurological improvement among patients with ischemic stroke undergoing endovascular thrombectomy: a randomized clinical trial. JAMA. (2016) 316:1986-96. doi: 10.1001/jama.2016.16623
71. Simonsen CZ, Yoo AJ, Sorensen LH, Juul N, Johnsen SP, Andersen $G$, et al. Effect of general anesthesia and conscious sedation during endovascular therapy on infarct growth and clinical outcomes in acute ischemic stroke: a randomized clinical trial. JAMA Neurol. (2018) 75:470-7. doi: 10.1001/jamaneurol.2017.4474

72. Talke PO, Sharma D, Heyer EJ, Bergese SD, Blackham KA, Stevens RD. Society for neuroscience in anesthesiology and critical care expert consensus statement: anesthetic management of endovascular treatment for acute ischemic stroke*: endorsed by the society of neurointerventional surgery and the neurocritical care society. J Neurosurg Anesthesiol. (2014) 26:95-108. doi: 10.1097/ANA.0000000000000042

73. Fiorella D, Fargen KM, Leslie-Mazwi TM, Levitt M, Probst S, Bergese S, et al. Neurointervention for emergent large vessel occlusion during the covid-19 pandemic. J Neurointerv Surg. (2020). doi: 10.1136/neurintsurg-2020-016117. [Epub ahead of print].

74. Office of Emergency Preparedness HSPP. Airborne Infectious Disease Management - Methods for Temporary Negative Pressure Isolation. Health MDO.

75. CDC. Guidelines for Environmental Infection Control in Health-Care Facilities 2003. (2003). Available online at: https://www.cdc.gov/infectioncontrol/ guidelines/environmental/appendix/air.html\#tableb1 (accessed April 8, 2020).

Conflict of Interest: The authors declare that the research was conducted in the absence of any commercial or financial relationships that could be construed as a potential conflict of interest.

Copyright $\odot 2020$ Salahuddin, Castonguay, Zaidi, Burgess, Jadhav and Jumaa. This is an open-access article distributed under the terms of the Creative Commons Attribution License (CC BY). The use, distribution or reproduction in other forums is permitted, provided the original author(s) and the copyright owner(s) are credited and that the original publication in this journal is cited, in accordance with accepted academic practice. No use, distribution or reproduction is permitted which does not comply with these terms. 